\author{
Abstracta Iranica \\ Abstracta Iranica Revue bibliographique pour le domaine irano-aryen \\ Volume 37-38-39 | 2018 \\ Comptes rendus des publications de 2014-2016
}

\title{
Nicholas Sims-Williams (ed.). The life of Serapion and other Christian Sogdian texts from the manuscripts E25 and E26
}

Florence Jullien

\section{(2) OpenEdition Journals}

Édition électronique

URL : http://journals.openedition.org/abstractairanica/45266

DOI : 10.4000/abstractairanica.45266

ISBN : 1961-960X

ISSN : 1961-960X

Éditeur :

CNRS (UMR 7528 Mondes iraniens et indiens), Éditions de l'IFRI

\section{Référence électronique}

Florence Jullien, « Nicholas Sims-Williams (ed.). The life of Serapion and other Christian Sogdian texts

from the manuscripts E25 and E26», Abstracta Iranica [En ligne], Volume 37-38-39 | 2018, document 44 mis en ligne le 30 décembre 2018, consulté le 26 septembre 2020. URL : http://

journals.openedition.org/abstractairanica/45266 ; DOI : https://doi.org/10.4000/abstractairanica 45266

Ce document a été généré automatiquement le 26 septembre 2020.

Tous droits réservés 


\title{
Nicholas Sims-Williams (ed.). The life of Serapion and other Christian Sogdian texts from the manuscripts E25 and E26
}

\author{
Florence Jullien
}

\section{RÉFÉRENCE}

Nicholas Sims-Williams (ed.). The life of Serapion and other Christian Sogdian texts from the manuscripts E25 and E26. Turnhout: Brepols, 2015, 298 p., 11 ill. ISBN 978-2-503-55536-2, (Berliner Turfantexte 35)

Les textes ici réunis proviennent des manuscrits de l'oasis de Turfan E25 et E26 de la collection berlinoise; ils sont traduits et minutieusement analysés avec des commentaires philologiques. Cet ensemble est particulièrement intéressant pour l'étude des interactions entre le sogdien et le syriaque ; en effet, il s'agit pour la plupart de récits hagiographiques traduits directement du syriaque mais avec des spécificités propres : la Vie de Sérapion par exemple présente des adaptations graphiques rares et des formes grammaticales inhabituelles qui témoignent de la volonté des auteurs sogdiens d'ajuster au plus près leur traduction par rapport à l'original. La version sogdienne de la Vie de Jean de Daylam, un moine syro-oriental († 738) qui fonda plusieurs monastères notamment dans le Huzistān, diffère sensiblement du texte connu en syriaque publié par S. P. Brock dans Parole de l'Orient (10, 1981, p. 123-189). Comme le précise l'A., cette version comporte ainsi certains détails inédits sur l'histoire de l'Iran occidental au début de la période islamique. Un autre texte consacré aux présages et aux augures présente des parallèles étroits avec les textes babyloniens sur le sujet - une survivance très ancienne qui montre aussi l'importance et la pérennité de ce phénomène dans la réalité des croyances des différentes communautés, notamment chrétiennes, du Moyen-Orient. Parmi les documents publiés dans cet ouvrage figure également une réfutation du manichéisme qui rend compte des échanges et des confrontations des chrétiens de Turfan avec les manichéens voisins. Ce travail se 
termine par un glossaire complet précédé de notes grammaticales, une bibliographie et un index des différents termes analysés. Onze planches de photos agrémentent également ce livre qui constitue un document précieux sur les langues iraniennes et syriaque, mais aussi pour notre connaissance de l'histoire de l'Asie centrale et des Églises orientales.

\section{AUTEURS}

\section{FLORENCE JULLIEN}

CNRS, Mondes iranien et indien, Paris 